\title{
Cytokines and chemokines associated with Treg/Th17 response in chronic inflammatory periapical disease
}

André Oliveira Naufel de TOLEDO(a) Aline Maria do COUTO(a) (1)

Mila Fernandes Moreira MADEIRA ${ }^{(b)}$

Patrícia Carlos CALDEIRA(a) (1)

Celso Martins QUEIROZ-JUNIOR(c)

Maria Cássia Ferreira de AGUIAR(a)

(a) Universidade Federal de Minas Gerais UFMG, School of Dentistry, Department of Oral Sugergy and Pathology, Belo Horizonte, Minas Gerais, Brazil.

(b) Universidade Federal de Minas Gerais - UFMG, Biological Sciences Institute, Department of Microbiology, Belo Horizonte, Minas Gerais, Brazil.

(c) Universidade Federal de Minas Gerais - UFMG, Biological Sciences Institute, Department of Morphology, Biological Sciences Institute, Belo Horizonte, Minas Gerais, Brazil.

Declaration of Interests: The authors certify that they have no commercial or associative interest that represents a conflict of interest in connection with the manuscript.

Corresponding Author:

Aline Maria do Couto

E-mail: alinemariacouto@hotmail.com

Submitted: March 23, 2019

Accepted for publication: August 2, 2019

Last revision: August 29, 2019
Abstract: Cytokines and chemokines have a fundamental role in the maintenance of inflammation and bone response, which culminate in the development of chronic periapical lesions. Regulatory (Treg) and Th17 cytokines play a key role in regulating the immune response involved in this process. The aim of this study was to investigate the role of Treg and Th17 cells in chronic inflammatory periapical disease, by comparing the expression of the immunoregulatory mediators TGF- $\beta$, IL-10, CCL4, and the proinflammatory IL-17 and CCL20 in the periapical tissue of teeth with pulp necrosis, with and without associated chronic lesions. Eighty-six periapical tissue samples were obtained from human teeth. The samples were divided into three groups: pulp necrosis with a periapical lesion $(n=26)$; pulp necrosis without a periapical lesion $(n=30)$, and control $(n=30)$. All samples were submitted to histopathological analysis and cytokine and chemokine measurement through ELISA. Statistical analyses were done with Kruskal-Wallis and Mann-Whitney tests and Spearman correlation. The group with pulp necrosis and a periapical lesion showed a higher expression of CCL4 and TGF- $\beta$ in comparison with pulp necrosis without a lesion. CCL20 was higher in the group with a periapical lesion when compared to the control. In all groups there was a weak positive correlation between IL-17/CCL20, IL-10/CCL4, and IL-17/TGF- $\beta$. Both types of cytokines, pro-inflammatory and immunoregulatory, occur simultaneously in periapical tissue. However, a rise in immunosuppressive cytokines and chemokines (CCL4 and TGF- $\beta$ ) in periapical lesions suggests a role of these cytokines in stable periapical disease.

Keywords: Cytokines; Endodontics; Periapical Diseases;

T-lymphocytes, Regulatory; Th17 Cells.

\section{Introduction}

Inflammatory periapical disease is a consequence of the host's defense response to aggression originating from the root canal, appearing mainly as a sequel of infection and necrosis of the pulp caused by dental caries. ${ }^{1}$ The immune response is fundamental in all stages of periapical disease. Bacteria and their metabolic products diffuse from the root canal and reach the dental apex stimulating first the innate immune-inflammatory response and then the adaptive immune response, which participate 
in the maintenance and progression of periapical chronic lesions. ${ }^{2}$

A complex cytokine network acts in the development of periapical lesions resulting in a more complex scenario than that from responses of the pro and anti-inflammatory mediators Th1 and Th2. ${ }^{3}$ Treg cells regulate Th1 and Th2 responses and play a central role in immunoregulation and induction of tolerance. ${ }^{4}$ Cytokines like TGF- $\beta$ and IL-10 control the proliferation and differentiation of naive T cells into Treg cells. ${ }^{5,6}$ The traffic of T lymphocytes to inflamed sites is mainly regulated by cytokines and their receptors, and in this sense, CCL4 plays an important role in the immunoregulatory process, recruiting Treg cells into inflammatory sites., ${ }^{7,8}$ The opposite role is exerted by Th17 cells, which produce the pro-inflammatory cytokine IL-17, among other mediators. IL-17 plays an important role in the induction of inflammation. ${ }^{9}$ Data suggests that the up-regulation and stable expression of CCR6 is a fundamental feature for Th17 differentiation. . . CCR6 is expressed on subsets of T cells and dendritic cells and it has CCL20 as its unique ligand. CCL20 also acts as a chemoattractant recruiting Th17 cells. ${ }^{11}$

In respect to periapical inflammatory disease, the regulation of both Treg and Th17 cells has been mostly explored in animal models, ${ }^{9,12}$ with only a few studies in humans. ${ }^{2,13,14}$ Several cytokines and chemokines like TGF- $\beta$, IL-10, IL-17, CCL4, and CCL20 are involved in the immune responses that take place during the development of these lesions. ${ }^{15}$ The presence of Treg cells was previously demonstrated in periapical lesions also expressing IL-10 and TGF- $\beta$ and causing a suppressive effect in the immune response. ${ }^{16}$ On the other hand, the production of IL-17 in periapical tissues was associated with an exacerbation of the inflammatory response, an elevated number of neutrophils, and bone resorption in human tissue. ${ }^{17}$ The results of these studies highlight the antagonism between Treg and Th17 cells, however, they do not demonstrate if this balance is different between periapical tissues of teeth with necrotic pulp that developed chronic inflammatory lesions and those that did not.

Therefore, this study aimed to investigate the role of Treg and Th17 cells in chronic inflammatory periapical disease, comparing the expression of the immunoregulatory mediators TGF- $\beta$, IL-10, CCL4 and the proinflammatory IL-17 and CCL20 in the periapical tissue of teeth with pulp necrosis with and without associated chronic lesions. Likewise, we intended to compare the balance of these cytokines and chemokines in both situations with the sound tissue, contributing to the understanding of the dynamics of periapical disease. The hypothesis of this study was that periapical tissues of teeth with pulp necrosis and associated chronic lesions have different concentrations of cytokines and chemokines compared with necrotic pulp teeth without associated lesions.

\section{Methodology}

The study was approved by the Institutional Committee of Ethics (CAAE - 398983.14.1.0000.5149) and all participants signed an informed consent form. Teeth $(n=86)$ from patients who had an indication for a tooth extraction were prospectively collected at the Oral Surgery Clinic by a single trained person (ANOT). The teeth were assigned to three groups: Group 1, pulp necrosis with a periapical lesion $(n=26)$; Group 2, pulp necrosis without a periapical lesion ( $\mathrm{n}=30)$; and Group 3 ( $\mathrm{n}=30$, control) healthy included or semi-included third molars. The periapical tissue was obtained by curettage of teeth after extraction (group 1) or by scrapping the roots with a scalpel blade (group 2 and 3).

For the control group, periapical tissues were obtained from teeth extracted due to orthodontic indications and healthy third molars with no inflammatory process. In groups 1 and 2, all teeth had caries. Deciduous teeth were not included but no distinctions were made regarding the tooth type. In the case of multi-rooted teeth, only the tissue of the affected root was collected. Before extraction, teeth were examined and the pulp vitality was assessed by clinical examination, pulp vitality tests (thermal and electrical), and radiographic exam. ${ }^{18}$ Teeth without pulp sensitivity and endodontic treatment indicated for extraction or endodontic apical surgery were included in the necrosis groups. Patients had no acute periapical symptoms at first appointment. Periapical lesions were characterized 
radiographically as radiolucent lesions, a widened periodontal ligament space, and discontinuity of the lamina dura. ${ }^{19}$ The diagnosis of periapical lesion was confirmed by histopathological exam.

The criteria for exclusion were patients with medical conditions requiring the use of systemic modifiers of bone metabolism (for example patients with mandibular osteonecrosis using bisphosphonates) or any other assisted drug therapy (systemic antibiotics, anti-inflammatory, or hormonal therapy) during the last 6 months before initiation of the study. Patients irradiated, with chronic periodontal disease, and pregnant or lactating women were excluded as well.

The periapical lesions were divided into two parts. One part was placed in 10\% buffered formalin for routine processing and histopathological analysis. The other part was placed in $1.5 \mathrm{~mL}$ Eppendorf tubes and stored in a temperature range between $-50^{\circ} \mathrm{C}$ to $-86^{\circ} \mathrm{C}$ for cytokine dosage through ELISA assay.

\section{Histopathological evaluation}

The lesions samples $(n=26)$ were routinely processed and included in paraffin, then slides were stained with hematoxylin and eosin for microscopic evaluation of the samples. A diagnosis of a dental granuloma or a radicular cyst was established by a trained oral pathologist (MCFA). Dental granulomas are composed of granulation tissue, i.e., a highly vascularized connective tissue interspersed by chronic inflammatory cells, without evidence of cavity formation or an epithelial lining. Radicular cysts are defined as cystic lesions lined by a non-keratinized stratified epithelium, which could (but may not) present hyperplasia, spongiosis, and exocytosis. The cyst capsule is of connective tissue with chronic inflammatory cells.

\section{Detection of tissue cytokines and chemokines}

The samples were weighed and homogenized in a buffer $(0.4 \mathrm{mM} \mathrm{NaCl}, 10 \mathrm{mM} \mathrm{NaPO}, \mathrm{pH} 7.4)$ containing protease inhibitors $(0.1 \mathrm{mM}$ phe- nylmethylsulfonyl fluoride, $0.1 \mathrm{mM}$ benzethonium chloride, $10 \mathrm{mMEDTA}$, and $0.01 \mathrm{mg} / \mathrm{mL}$ aprotinin $\mathrm{A}$ ) and polysorbate 20 (0.05\%), $\mathrm{pH} 7.4$, at a ratio of $1 \mathrm{~mL}$ solution per $100 \mathrm{mg}$ tissue. The homogenate was centrifuged $(8,946 \mathrm{~g})$ at $4^{\circ} \mathrm{C}$ for 10 minutes. The supernatant was then collected and used for the quantification of chemokines. The levels of TGF-b, IL-17, IL-10, CCL20, and CCL4 were evaluated by ELISA, using commercially available kits (TGF- $\beta$ and IL-10 from R\&D Systems Europe Ltd., Abington, UK; IL-17, CCL4 and CCL20 from Abcam Plc Europe Ltd., Cambridge, UK). All assays were carried out according to the manufacturer's instructions. Samples were analyzed in duplicate. Concentration correction of cytokines and chemokines was done by the weight of each sample. This concentration was calculated according to the standard curve provided by the manufacturer of each kit used. The results were reported as picograms of cytokines or chemokines per $100 \mathrm{mg}$ of tissue.

\section{Statistical analyses}

Statistical analyses were performed using the Statistical Package for the Social Sciences (SPSS) software, version 22.0 (SPSS Inc., Chicago, USA). Normal distribution was tested using theShapiro-Wilk procedure. Kruskal-Wallis and Mann-Whitney U tests were used for analyses of data with non-normal distributions. After applying the Bonferroni correction, statistical significance was considered when $P$ values were $<0.017$. Cytokine and chemokine levels were compared among the periapical lesion, pulp necrosis without a periapical lesion, and control groups. The Spearman correlation test was performed for the cytokines and chemokines IL-17/CCL20, IL-10/CCL4, and IL-17/TGF- $\beta$.

\section{Results}

The groups were composed of 26 periapical lesions (donors' age ranged from 19 to 51 years), 30 pulp necroses with no lesion (donors' age ranged from 22 to 58 years), and 30 controls (donors' age ranged from 18 to 27 years). Periapical lesions were composed of 19 dental granulomas $(73.1 \%)$ and 7 radicular cysts (26.9\%), but were not evaluated separately.

The levels of TGF- $\beta$, CCL4, and CCL20 were different among groups. TGF- $\beta$ and CCL4 were higher in the periapical lesion group than in the necrosis/no lesion group ( $p=0.002$ and $p=0.001$, respectively). TGF- $\beta$ level was significantly lower 
in the necrosis/no lesion group compared to the control group $(p=0.017)$, but the difference was not significant between the periapical lesion group and control group $(p=0.153)$. CCL4 and CCL20 had higher levels in the periapical lesion group than the control ( $p<0.001)$, however their levels were not statistically different between group 2 and the control ( $p=0.378$ and $p=0.036$ respectively). CCL20 levels were not different between the groups with pulp necrosis ( $p=0.057$ ). Regarding the IL-10 and IL-17 cytokines, there was no significant difference between the groups (Tables 1 and 2).

In all groups there was a weak positive correlation between IL-10/CCL4 $(r=0.285)$. The weak positive correlation observed between IL-17/CCL20 ( $r=0.036)$ and IL-17/TGF- $\beta(\mathrm{r}=0.021)$ was not statistically significant (Table 3 ).

\section{Discussion}

Th17 and Treg cells have opposite roles in the immune response process of inflammatory periapical disease. The principal cytokines and chemokines produced by those cells are TGF, IL-10, CCL4, CCL20, and IL-17. While Treg cells have a regulatory action mediated by TGF, IL-10, and
CCL4, ${ }^{2,7}$ the recruitment of Th17 cells is mediated via the interaction of their receptor, CCR6, with the chemokine CCL20, ${ }^{20}$ which stimulates the local inflammatory cells to produce the cytokine IL-17. ${ }^{5}$ This study explored a possible difference in this balance considering the presence or not of a periapical lesion, compared with controls.

TGF- $\beta$ and CCL- 4 levels were raised in the group with a periapical lesion compared to the group without a lesion. The increase in the expression of TGF- $\beta$ in periapical lesions is possibly explained by the fact that cells producing this cytokine, such as eosinophils, lymphocytes, fibroblasts, and monocytes ${ }^{21}$ are found in high numbers in these lesions ${ }^{22}$. In addition, the increase of TGF- $\beta 1$ in periapical lesions with more severe inflammation ${ }^{2}$ may also be explained by an attempt to regulate the immunological mechanisms triggered in these lesions; thus, more advanced lesions imply a more complex regulatory response than early lesions. ${ }^{13}$

The increase of Treg regulators, especially TGF- $\beta$ in chronic periapical lesions, is in accordance with other studies. ${ }^{23,24}$ TGF- $\beta$ can contribute to the stabilization of periapical lesions through its modulating effect on bone resorption activities mediated by the proinflammatory action of cytokines. ${ }^{22}$

Table 1. Descriptive analysis and comparison of the cytokine and chemokine levels among groups.

\begin{tabular}{|c|c|c|c|c|}
\hline Cytokine/ chemokine & Groups & Mean & Std. deviation & $\mathrm{p}$-value* \\
\hline TGF- $\beta$ & Control & 482.20 & 511.54 & \\
\hline \multirow{2}{*}{ (pg/100 mg tissue) } & Necrosis without lesion & 274.58 & 582.64 & \\
\hline & Necrosis with lesion & 921.31 & 911.22 & $0.004^{* *}$ \\
\hline IL10 & Control & 208.51 & 438.41 & \\
\hline \multirow{2}{*}{ (pg/100 mg tissue) } & Necrosis without lesion & 6565.19 & 18152.98 & \\
\hline & Necrosis with lesion & 709.18 & 1875.40 & 0.328 \\
\hline IL17 & Control & 76.10 & 51.37 & \\
\hline \multirow{2}{*}{ (pg/100 mg tissue) } & Necrosis without lesion & 75.53 & 76.42 & \\
\hline & Necrosis with lesion & 79.52 & 60.55 & 0.633 \\
\hline CCL4 & Control & 121.69 & 152.59 & \\
\hline \multirow{2}{*}{ (pg/100 mg tissue) } & Necrosis without lesion & 151.85 & 157.03 & \\
\hline & Necrosis with lesion & 657.82 & 704.24 & $<0.001^{* *}$ \\
\hline CCL20 & Control & 45.13 & 23.53 & \\
\hline \multirow{2}{*}{ (pg/100 mg tissue) } & Necrosis without lesion & 64.39 & 44.88 & \\
\hline & Necrosis with lesion & 95.72 & 112.60 & $0.001^{* *}$ \\
\hline
\end{tabular}

*Kruskal Wallis Test. ${ }^{* *}$ Statistically significant $(p<0.05)$. 
Table 2. Statistical comparison of cytokine and chemokine levels among groups.

\begin{tabular}{lcc}
\hline Groups & $\begin{array}{c}\text { Cytokine/ } \\
\text { chemokine }\end{array}$ & p-value \\
\hline Control X & TGF- $\beta$ & 0.153 \\
Necrosis with lesion & CCL4 & $<0.001^{* *}$ \\
Necrosis without lesion X & CCL20 & $<0.001^{* *}$ \\
Necrosis with lesion & TGF- $\beta$ & $0.002^{* *}$ \\
Control X & CCL4 & $0.001^{* *}$ \\
Necrosis without lesion & CCL20 & 0.057 \\
& TGF- $\beta$ & $0.017^{* *}$ \\
\hline
\end{tabular}

* Mann-Whitney U Test. ${ }^{* *}$ Statistically significant $(p<0.017)$.

Table 3. Spearman correlation of the cytokines and chemokines IL-17/CCL20, IL-10/CCL4 and IL-17/ TGF- $\beta$.

\begin{tabular}{lcc}
\hline Variables & Correlation coefficient $(r)$ & $p$-value \\
\hline IL-17 & 0.036 & 0.768 \\
CCL20 & & \\
IL-10 & 0.285 & $0.050^{*}$ \\
CCL4 & & \\
IL-17 & 0.021 & 0.875 \\
TGF- $\beta$ & & \\
\hline
\end{tabular}

*Statistically significant ( $p \leq 0.05)$.

In the present study, TGF- $\beta$, as well as other mediators, were also found in control tissues. This is not surprising, since this mediator is important in all physiological processes, contributing to the timely repair of injuries by the inhibition of bone resorption. ${ }^{24}$ The control samples used in the present study were periapical tissues removed from a healthy tooth. Other studies opted to use dental pulp from impacted teeth as a control group. ${ }^{17,25}$ Although our control tissue presented the advantage of being of the same nature as the diseased tissue, this might have allowed the inclusion of a very mild inflammatory process. Another interesting result was the increase in TGF- $\beta$ expression in the control group compared to the group with necrosis and no lesion. This result might have been influenced by the inclusion of tissues from teeth extracted for orthodontic reasons in the control group. In this respect, it is known that TGF- $\beta 1$ is a cytokine importantly associated with the process of bone remodeling that occurs during dental movement in orthodontic treatment. ${ }^{26}$

The roles of CCL20 and CCL4 in regulating the infiltration of Treg and CTL lymphocytes have already been demonstrated in other types of lesions, ${ }^{27,28}$ but there are not studies on periapical disease. In the present study we found raised levels of CCL20 and CCL4 in periapical tissues of necrotic teeth. CCL20 is also involved in the recruitment of Th17 lymphocytes in chronic inflammatory processes of the liver, ${ }^{29}$ triggering a pro-inflammatory response, for example, by the expression of the cytokine IL17. Considering this fact, it is interesting that we found a positive correlation between IL-17 and CCL20, similar to another study. ${ }^{27}$ Although the correlation was weak, this observation may indicate that CCL20 recruits both Treg and Th17, lymphocytes that have opposite functions. ${ }^{27}$

Thus, the higher CCL20 expression in the periapical lesion group compared to the control group is implied with this dual function, suggesting that the triggering of a proinflammatory response, through the expression of the cytokine IL17, which at the same time is regulated via Treg cells and their mediators, contribute to the stability of those lesions. In fact, chronic periapical lesions can suffer a re-acutization process, which is correlated with an increase in leukocyte infiltration in the region, especially neutrophils, in addition to an increase of IL-17.,17 Studies have demonstrated an increase in IL17 expression in chronic periapical diseases undergoing re-acutization. ${ }^{3,17}$

Higher CCL4 levels were found in the periapical lesion group compared with the no lesion and control groups. This finding is interesting since this chemokine is related to the migration of CD8+ T lymphocytes, ${ }^{27}$ responsible for important effector activities in the elimination of intracellular pathogens. ${ }^{30}$ A study demonstrated that CCL4 was the most potent chemoattractant of Treg cells, suggesting that the recruitment of regulatory $\mathrm{T}$ cells by CCL4 plays a central role in the start of the humoral response. ${ }^{7}$ Therefore, the fact that CCL4 is related to the migration of Treg lymphocytes, ${ }^{31}$ which are capable of producing the immunosuppressive 
cytokine IL-10, ${ }^{32}$ might explain the positive correlation between IL-10 and CCL4 observed in our study. Thus, this immunosuppressive feature can represent a protective mechanism against bone destruction in the course of a periapical lesion.

Although weak, we found a positive correlation between IL-17 and TGF- $\beta$. These cytokines have an antagonist effect in periapical disease. While IL-17 causes exacerbation of inflammation in chronic periapical lesions, ${ }^{33}$ TGF- $\beta$ has immunosuppressive activities and promotes healing in the periapical region. ${ }^{34}$ However, although TGF- $\beta$ has an immunosuppressive action, ${ }^{34}$ when it acts together with IL-6, it induces the differentiation of Th17 cells from naive precursors, ${ }^{33}$ promotes the production of IL-17,35 and in contrast, inhibits the development of Treg cells. ${ }^{36}$ Thus, the combined action of TGF- $\beta$ and IL- 6 (produced by the innate immune system activated by infection) may "dictate" the balance between Treg and Th17 cells in the immune system. ${ }^{36}$ Therefore, in the present study, the absence of IL-6 in the panel of analyzed cytokines was a limitation. Future research including the dosage of IL6 in an in vivo model similar to the present study is important to improve knowledge about controlling immune responses in periapical disease.

In this study, samples of radicular cysts and granulomas were not evaluated separately. Although some studies indicate a more inflamed profile for radicular cysts in comparison with granulomas, ${ }^{24,25}$ our results are in accordance with others, ${ }^{22,23}$ showing a predominance of an anti-inflammatory profile in chronic periapical disease. For future studies, the classification into either active or inactive lesions ${ }^{3}$ rather than the histopathological type might be a more realistic analysis for chronic periapical disease.

In conclusion, this study showed the simultaneous immunosuppressive and pro-inflammatory features of chronic periapical lesions represented respectively by IL-10/TGF- $\beta$ /CCL4 and IL-17/CCL20, with a predominance of Treg cytokines and chemokines, especially TGF- $\beta$. In all groups there was a weak positive correlation between IL-17/CCL20, IL-10/CCL4, and IL-17/TGF- $\beta$. These results suggest that the response of Treg/Th17 in chronic periapical lesions occurs not as a balance but as a co-stimulation mechanism. A large difference was not found between the pulp necrosis groups, however higher levels of Treg cytokines, especially TGF- $\beta$, were found in periapical lesions group than in necrotic teeth without a lesion, suggesting a role of this cytokine in the maintenance of periapical disease. Further research is needed on the dynamics of periapical inflammation and cytokine regulation network, employing a large panel of markers and focusing on the different stages of periapical disease.

\section{Conclusion}

The results of the present study showed that the Treg/Th17 profile in periapical tissues of necrotic teeth seems to be regulated by a co-stimulatory mechanism with pro-inflammatory and immunoregulatory mediators occurring simultaneously. In addition, the higher levels of immunoregulatory cytokines CCL4 and TGF- $\beta$ in the presence of lesions probably contributes to their persistence.

\section{Acknowledgments}

This work was supported by Conselho Nacional de Desenvolvimento Científico e Tecnológico (CNPq), Coordenação de Aperfeiçoamento de Pessoal de Nível Superior (CAPES), and Fundação de Amparo à Pesquisa do Estado de Minas Gerais (FAPEMIG), Brazil.

\section{References}

1. Molander A, Warfvinge J, Reit C, Kvist T. Clinical and radiographic evaluation of one- and two-visit endodontic treatment of asymptomatic necrotic teeth with apical periodontitis: a randomized clinical trial. J Endod. 2007 Oct;33(10):1145-8. https://doi.org/10.1016/i.joen.2007.07.005 
2. Andrade AL, Nonaka CF, Gordón-Núñez MA, Freitas RA, Galvão HC. Immunoexpression of interleukin 17, transforming growth factor $\beta 1$, and forkhead box P3 in periapical granulomas, radicular cysts, and residual radicular cysts. J Endod. 2013 Aug;39(8):990-4. https://doi.org/10.1016/i.joen.2013.04.028

3. Araujo-Pires AC, Francisconi CF, Biguetti CC, Cavalla F, Aranha AM, Letra A, et al. Simultaneous analysis of T helper subsets (Th1, Th2, Th9, Th17, Th22, Tfh, Trl and Tregs) markers expression in periapical lesions reveals multiple cytokine clusters accountable for lesions activity and inactivity status. J Appl Oral Sci. 2014 Jul-Aug;22(4):336-46. https://doi.org/10.1590/1678-775720140140

4. Ziegler SF, Buckner JH. FOXP3 and the regulation of Treg/Th17 differentiation. Microbes Infect. 2009 Apr;11(5):594-8. https://doi.org/10.1016/j.micinf.2009.04.002

5. Noack M, Miossec P. Th17 and regulatory T cell balance in autoimmune and inflammatory diseases. Autoimmun Rev. 2014 Jun;13(6):668-77. https://doi.org/10.1016/i.autrev.2013.12.004

6. Tesmer LA, Lundy SK, Sarkar S, Fox DA. Th17 cells in human disease. Immunol Rev. 2008 Jun;223(1):87-113. https://doi.org/10.1111/j.1600-065X.2008.00628.x

7. Bystry RS, Aluvihare V, Welch KA, Kallikourdis M, Betz AG. B cells and professional APCs recruit regulatory T cells via CCL4. Nat Immunol. 2001 Dec;2(12):1126-32. https://doi.org/10.1038/ni735

8. Harlin H, Meng Y, Peterson AC, Zha Y, Tretiakova M, Slingluff C, et al. Chemokine expression in melanoma metastases associated with CD8+ T-cell recruitment. Cancer Res. 2009 Apr;69(7):3077-85. https://doi.org/10.1158/0008-5472.CAN-08-2281

9. Yang S, Zhu L, Xiao L, Shen Y, Wang L, Peng B, et al. Imbalance of interleukin-17+ T-cell and Foxp3+ regulatory T-cell dynamics in rat periapical lesions. J Endod. 2014 Jan;40(1):56-62. https://doi.org/10.1016/i.joen.2013.09.033

10. Singh SP, Zhang HH, Foley JF, Hedrick MN, Farber JM. Human T cells that are able to produce IL-17 express the chemokine receptor CCR6. J Immunol. 2008 Jan;180(1):214-21. https://doi.org/10.4049/jimmunol.180.1.214

11. Kitamura K, Farber JM, Kelsall BL. CCR6 marks regulatory T cells as a colon-tropic, IL-10-producing phenotype. J Immunol. 2010 Sep;185(6):3295-304. https://doi.org/10.4049/jimmunol.1001156

12. AlShwaimi E, Purcell P, Kawai T, Sasaki H, Oukka M, Campos-Neto A, et al. Regulatory T cells in mouse periapical lesions. J Endod. 2009 Sep;35(9):1229-33. https://doi.org/10.1016/i.joen.2009.06.006

13. Colić M, Gazivoda D, Vucević D, Vasilijić S, Rudolf R, Lukić A. Proinflammatory and immunoregulatory mechanisms in periapical lesions. Mol Immunol. 2009 Nov;47(1):101-13. https://doi.org/10.1016/i.molimm.2009.01.011

14. Naufel AO, Aguiar MC, Madeira FM, Abreu LG. Treg and Th17 cells in inflammatory periapical disease: a systematic review. Braz Oral Res. 2017 Dec;31(0):e103. https://doi.org/10.1590/1807-3107bor-2017.vol31.0103

15. Nair PN. Pathogenesis of apical periodontitis and the causes of endodontic failures. Crit Rev Oral Biol Med. 2004 Nov;15(6):348-81. https://doi.org/10.1177/154411130401500604

16. Colić M, Gazivoda D, Vucević D, Majstorović I, Vasilijić S, Rudolf R, et al. Regulatory T-cells in periapical lesions. J Dent Res. 2009 Nov;88(11):997-1002. https://doi.org/10.1177/0022034509347090

17. Marçal JR, Samuel RO, Fernandes D, Araujo MS, Napimoga MH, Pereira SA, et al. T-helper cell type 17/regulatory T-cell immunoregulatory balance in human radicular cysts and periapical granulomas. J Endod. 2010 Jun;36(6):995-9. https://doi.org/10.1016/i.joen.2010.03.020

18. Jafarzadeh H, Abbott PV. Review of pulp sensibility tests. Part II: electric pulp tests and test cavities. Int Endod J. 2010 Nov;43(11):945-58. https://doi.org/10.1111/j.1365-2591.2010.01760.x

19. Huumonen S, Ørstavik D. Radiological aspects of apical periodontitis. Endod Topics. 2002;1(1):3-25. https://doi.org/10.1034/i.1601-1546.2002.10102.x

20. Walch-Rückheim B, Mavrova R, Henning M, Vicinus B, Kim YJ, Bohle RM, et al. Stromal Fibroblasts Induce CCL20 through IL6/C/ EBP $\beta$ to Support the Recruitment of Th17 Cells during Cervical Cancer Progression. Cancer Res. 2015 Dec;75(24):5248-59. https://doi.org/10.1158/0008-5472.CAN-15-0732

21. Tyler LW, Matossian K, Todd R, Gallagher GT, White RR, Wong DT. Eosinophil-derived transforming growth factors (TGF-alpha and TGF-beta 1) in human periradicular lesions. J Endod. 1999 Sep;25(9):619-24. https://doi.org/10.1016/S0099-2399(99)80322-7

22. Danin J, Linder LE, Lundqvist G, Andersson L. Tumor necrosis factor-alpha and transforming growth factor-betal in chronic periapical lesions. Oral Surg Oral Med Oral Pathol Oral Radiol Endod. 2000 Oct;90(4):514-7. https://doi.org/10.1067/moe.2000.108958

23. Liang ZZ, Li J, Huang SG. Transforming growth factor beta-1 expression in macrophages of human chronic periapical diseases. Genet Mol Res. 2017 Mar;16(1). https://doi.org/10.4238/gmr16019329

24. Dessaune Neto N, Porpino MT, Antunes HD, Rodrigues RC, Perez AR, Pires FR, et al. Pro-inflammatory and antiinflammatory cytokine expression in post-treatment apical periodontitis. J Appl Oral Sci. 2018 Jun;26(0):e20170455. https://doi.org/10.1590/1678-7757-2017-0455 
- Cytokines and chemokines associated with Treg/Th17 response in chronic inflammatory periapical disease

25. Teixeira-Salum TB, Rodrigues DB, Gervásio AM, Souza CJ, Rodrigues V Jr, Loyola AM. Distinct Th1, Th2 and Treg cytokines balance in chronic periapical granulomas and radicular cysts. J Oral Pathol Med. 2010 Mar;39(3):250-6. https://doi.org/10.1111/j.1600-0714.2009.00863.x

26. Uematsu S, Mogi M, Deguchi T. Increase of transforming growth factor-beta 1 in gingival crevicular fluid during human orthodontic tooth movement. Arch Oral Biol. 1996 Nov;41(11):1091-5. https://doi.org/10.1016/S0003-9969(96)00063-5

27. Liu JY, Li F, Wang LP, Chen XF, Wang D, Cao L, et al. CTL- vs Treg lymphocyte-attracting chemokines, CCL4 and CCL20, are strong reciprocal predictive markers for survival of patients with oesophageal squamous cell carcinoma. Br J Cancer. 2015 Sep;113(5):747-55. https://doi.org/10.1038/bjc.2015.290

28. Zhang CY, Qi Y, Li XN, Yang Y, Liu DL, Zhao J, et al. The role of CCL20/CCR6 axis in recruiting Treg cells to tumor sites of NSCLC patients. Biomed Pharmacother. 2015 Feb;69:242-8. https://doi.org/10.1016/i.biopha.2014.12.008

29. Zhao J, Zhang Z, Luan Y, Zou Z, Sun Y, Li Y, et al. Pathological functions of interleukin-22 in chronic liver inflammation and fibrosis with hepatitis B virus infection by promoting T helper 17 cell recruitment. Hepatology. 2014 Apr;59(4):1331-42. https://doi.org/10.1002/hep.26916

30. Rodrigues EG, Zavala F, Eichinger D, Wilson JM, Tsuji M. Single immunizing dose of recombinant adenovirus efficiently induces CD8+ T cell-mediated protective immunity against malaria. J Immunol. 1997 Feb;158(3):1268-74.

31. Schlecker E, Stojanovic A, Eisen C, Quack C, Falk CS, Umansky V, et al. Tumor-infiltrating monocytic myeloid-derived suppressor cells mediate CCR5-dependent recruitment of regulatory T cells favoring tumor growth. J Immunol. 2012 Dec;189(12):5602-11. https://doi.org/10.4049/jimmunol.1201018

32. Shevach EM. Mechanisms of foxp3+ T regulatory cell-mediated suppression. Immunity. 2009 May;30(5):636-45. https://doi.org/10.1016/i.immuni.2009.04.010

33. Colić M, Vasilijić S, Gazivoda D, Vucević D, Marjanović M, Lukić A. Interleukin-17 plays a role in exacerbation of inflammation within chronic periapical lesions. Eur J Oral Sci. 2007 Aug;115(4):315-20. https://doi.org/10.1111/j.1600-0722.2007.00460.x

34. Lukić A. Transforming growth factor-beta is a major down-regulatory cytokine in periapical lesions. Balkan Stomatol. 2000;4:157-60.

35. Langrish CL, Chen Y, Blumenschein WM, Mattson J, Basham B, Sedgwick JD, et al. IL-23 drives a pathogenic T cell population that induces autoimmune inflammation. J Exp Med. 2005 Jan;201(2):233-40. https://doi.org/10.1084/jem.20041257

36. Bettelli E, Oukka M, Kuchroo VK. T(H)-17 cells in the circle of immunity and autoimmunity. Nat Immunol. 2007 Apr;8(4):345-50. https://doi.org/10.1038/ni0407-345 